\title{
p53 causes butein-mediated apoptosis of chronic myeloid leukemia cells
}

\author{
SANG-MI WOO ${ }^{1}$, YOUN KYNUG CHOI ${ }^{1}$, AH JEONG KIM $^{1}$, SUNG-GOOK CHO $^{2}$ and SEONG-GYU KO ${ }^{1}$ \\ ${ }^{1}$ Department of Preventive Medicine, College of Korean Medicine, Kyung Hee University, Seoul 130-701; \\ ${ }^{2}$ Department of Biotechnology, Korea National University of Transportation, \\ Chungju, Chungbuk 368-701, Republic of Korea
}

Received November 24, 2014; Accepted August 4, 2015

DOI: $10.3892 / \mathrm{mmr} .2015 .4672$

\begin{abstract}
Progression of chronic myeloid leukemia, marked by the oncogenic $B c r-A b l$ mutation, is tightly associated with an alteration of the p53 pathway. It is known that butein extracted from various plants represses cancer growth. Although the anticancer effects of butein are widely accepted, the mechanisms by which butein induces apoptosis of chronic myeloid leukemia cells remains to be elucidated. The present study demonstrated that butein-induced apoptosis was mediated by p53. KBM5 chronic myeloid leukemia (CML) cells expressing wild-type p53 were more sensitive to butein compared with p53-null K562 CML cells in terms of apoptotic cell death. In addition, butein arrested KBM5 cells at S-phase and altered the expression levels of certain cyclins and the p53-downstream targets, MDM2 and p21. In addition, while butein reduced the protein expression of MDM2 in the KBM5 and K562 cells, it resulted in proteasome-independent MDM2 degradation in p53-expressing KBM5 cells, however, not in p53-null K562 cells. Therefore, the present study suggested that p53 causes the butein-mediated apoptosis of leukemic cells.
\end{abstract}

\section{Introduction}

Chronic myeloid leukemia (CML) is a cancerous disease in which blood cells lose the ability to perform their normal roles (1), increasing the risk of bleeding more easily, infection and anemia in patients with CML (2). CML is associated with the oncogenic $B C R-A B L$ gene mutation in the Philadelphia chromosome, where chromosomal translocation, $\mathrm{t}(9 ; 22)(\mathrm{q} 34 ; \mathrm{q} 11.2)$ causes a fusion of Abelson $(A B L)$

Correspondence to: Dr Seong-Gyu Ko, Department of Preventive Medicine, College of Korean Medicine, Kyung Hee University, 1 Hoegi-dong, Dongdaemun-gu, Seoul 130-701, Republic of Korea E-mail: epiko@khu.ac.kr

Key words: butein, chronic myeloid leukemia, p53, MDM2, apoptosis at chromosome $9 \mathrm{q} 34$ with the breakpoint cluster region $(B C R)$ at chromosome $22 \mathrm{q} 11.2$ (3). It was revealed that the $B C R-A B L$ gene product increases the expression of MDM2, a negative regulator of p53 (4). MDM2, a regulator of p53, is an E3 ubiquitin-ligase, regulating the stability of p53 (5). Loss of p53 is associated with the progression of CML (6) and p53 stabilization in CML cells causes apoptosis (7-9).

Butein (3,4,2',4'-tetrahydroxychalcone), extracted from Rhus verniciflua stokes, stem-bark of cashews (Semecarpus anacardium) or the heartwood of Dalbergia odorifera (10-13), exerts an anticancer effect in various types of cancer, including breast cancer $(14,15)$, prostate cancer $(16)$, lymphoma (11) and leukemia (17). In leukemia cells, butein has been demonstrated to induce tumor necrosis factor-related apoptosis-inducing ligand-mediated apoptosis (17). However, while chalcones, including butein, caused the apoptosis of mouse melanoma cells independently of p53 (18), p53 dependency in butein-mediated apoptotic cell death remains to be elucidated.

The present study assessed the apoptotic effect of butein on two different CML cell lines, KBM5 and K562. The KBM5 cells express wild-type p53 and the K562 cells express no p53 $(19,20)$. Therefore, these cell lines provided a clear model to determine whether the butein effect on apoptotic cell death of CML cells was associated with the expression of $\mathrm{p} 53$. Understanding the mechanisms underlying butein treatment is useful for developing drugs to inhibit the progression of CML.

\section{Materials and methods}

Reagents and cell lines. Butein (3,4,2',4'-tetrahydroxychalcone) was purchased from Santa Cruz Biotechnology, Inc. (Santa Cruz, CA, USA). MG132 and cycloheximide were purchased from Calbiochem (La Jolla, CA, USA). The caspase inhibitor, Z-VAD-FMK, was purchased from Promega (Madison, WI, USA). The KBM5 and K562 cell lines were kindly given by Dr Bharat B Aggarwal (University of Texas M.D. Anderson Cancer Center, Houston, TX, USA) and from Dr Dong-Hoon Jin (Asan Medical Center, Seoul, Korea), respectively. The cells were cultured in Iscove's modified Dulbecco's medium, supplemented with $10 \%$ fetal bovine serum and $1 \%$ antibiotics (Welgene, Inc., Daegu, Korea). 
Cell viability and trypan blue assay. A total of $2 \times 10^{4}$ cells (for either the KBM5 or the K562 cell line) were seeded into each well of 96-well plates and were subsequently treated with butein at different concentrations for $24 \mathrm{~h}$. The cell viability was measured using an EZ-Cytox Enhanced Cell Viability assay kit (DoGen, Seoul, Korea), according to the manufacturer's instructions. Trypan blue assays were performed to measure cell growth. The cells were treated with various concentrations of butein for $72 \mathrm{~h}$ and the viable cell numbers were quantified daily.

Western blotting. Whole cell extracts were lysed in cell lysis buffer (Biosesang, Inc., Seongnam, Korea). Equal quantities of protein $(30 \mu \mathrm{g})$ were separated on $8-12 \%$ SDS-PAGE gels and were subsequently transferred onto a polyvinylidene difluoride membrane (GE Healthcare Life Sciences, Freiburg im Breisgau, Germany). After blocking the membranes with $1 \%$ bovine serum albumin and $2 \%$ skimmed milk for $1 \mathrm{~h}$, the membranes were incubated at $4^{\circ} \mathrm{C}$ overnight with the appropriate primary antibody, and were washed three times in phosphate buffered saline with $0.01 \%$ Tween-20. The membranes were incubated at room temperature for $1 \mathrm{~h}$ with horseradish peroxidase-conjugated secondary antibodies. In order to visualize the protein bands, the membranes were treated with enhanced chemiluminescence kit solution (DoGen) and exposed to X-ray film (AGFA Healthcare, Mortsel, Belgium). Anti-PARP, caspase-3, caspase-9, cyclin-dependent kinase (CDK)4, phosphorylated (p-)p53 and p-murine double minute 2 (MDM2) antibodies were obtained from Cell Signaling Technology, Inc. (Danvers, MA, USA). Anti-CDK1, CDK2, cyclin E, cyclin A, cyclin B, p21, p53 and $\mathrm{Bcl}-2$ antibodies were purchased from Santa Cruz Biotechnology, Inc. Anti-cyclin D and Bcl-xL antibodies were obtained from BD Biosciences (San Jose, CA, USA). The anti-tubulin antibody was obtained from Sigma-Aldrich, Inc. (St. Louis, MO, USA).

Reverse transcription-polymerase chain reaction (RT-PCR). The total RNA was extracted using a total RNA Extraction kit (Intron Biotechnology, Inc., Seongnam, Korea). The cDNA was synthesized using a cDNA synthesis kit (Takara Bio, Inc., Shiga, Japan), according to manufacturer's instructions. MDM 2 mRNA amplification was then performed with cDNA $(1 \mu \mathrm{g} / \mu \mathrm{l})$ and the following primers: forward, 5'-CTGGGGAGTCTTGAGGGACC-3' and reverse, 5'-CA GGTTGTCTAAATTCCTAG-3' (21). The cycling conditions used were as follows: denaturation at $94^{\circ} \mathrm{C}$ for $30 \mathrm{sec}$, annealing at $53^{\circ} \mathrm{C}$ for $1 \mathrm{~min}$, and elongation at $68^{\circ} \mathrm{C}$ for $2 \mathrm{~min}$. After 35 cycles, the $M D M 2$ mRNA band was visualized using a Davinch-Chemi ${ }^{\mathrm{TM}}$ Chemiluminescence Imaging system (Davinch-K Co., Ltd., Seoul, Korea).

Flow cytometry. To assess the cell cycle profile, the cells were treated with butein and were subsequently fixed in $95 \%$ ethanol with $0.5 \%$ Tween- 20 at $-20^{\circ} \mathrm{C}$ overnight. The fixed cells were stained with $50 \mu \mathrm{g} / \mathrm{ml}$ propidium iodide (Santa Cruz Biotechnology, Inc.). For apoptotic cell death, the cells were treated with butein and subsequently stained with annexin V and 7-aminoactinomycin D (7-AAD; Santa Cruz Biotechnology, Inc.). The cells were analyzed using a
A<smiles>O=C(/C=C/c1ccc(O)c(O)c1)c1ccc(O)cc1O</smiles>

B

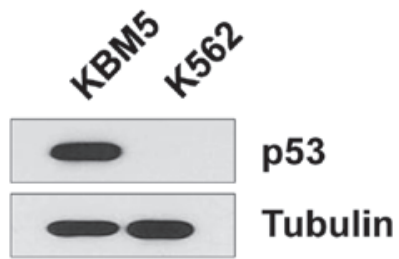

C

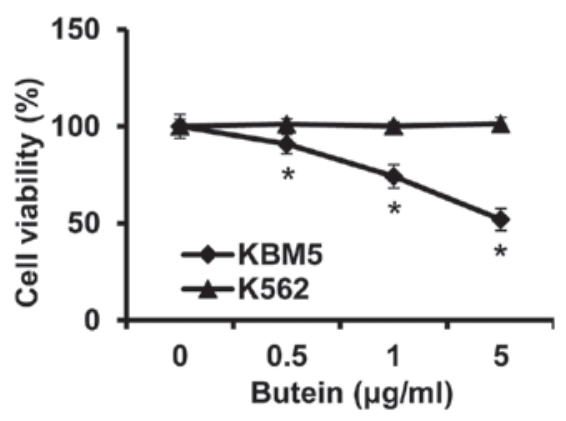

D
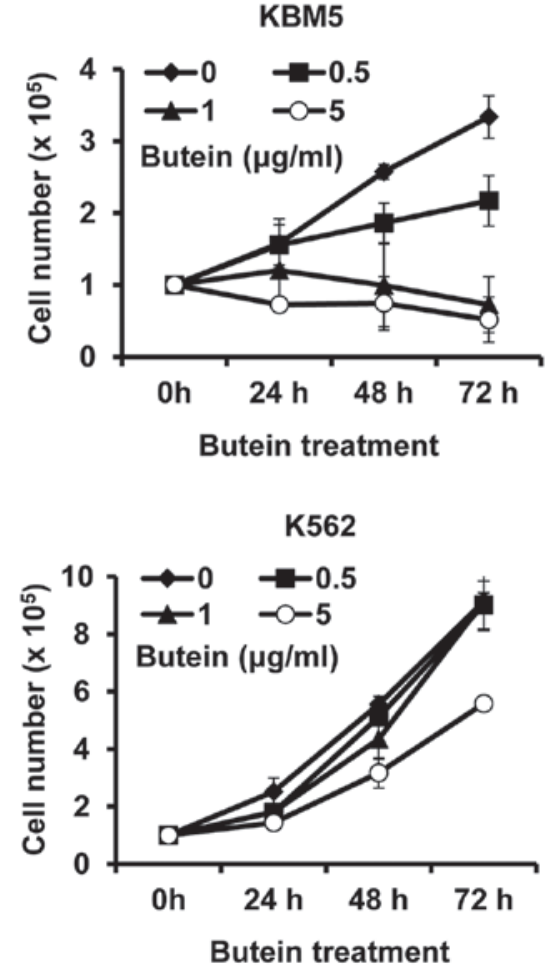

Figure 1. Effect of butein on CML cell growth and viability. (A) The chemical structure of butein. (B) The protein expression of p53 in CML cells was determined by western blotting. (C) Cell viability assays were performed following treatment with butein at various concentrations for $24 \mathrm{~h}$. (D) The cells were treated with butein at various concentrations for 24,48 or $72 \mathrm{~h}$. Viable cells were counted daily following staining cells with trypan blue. All experiments were performed in triplicate $\left({ }^{*} \mathrm{P}<0.05\right)$. CML, chronic myeloid leukemia. 
A
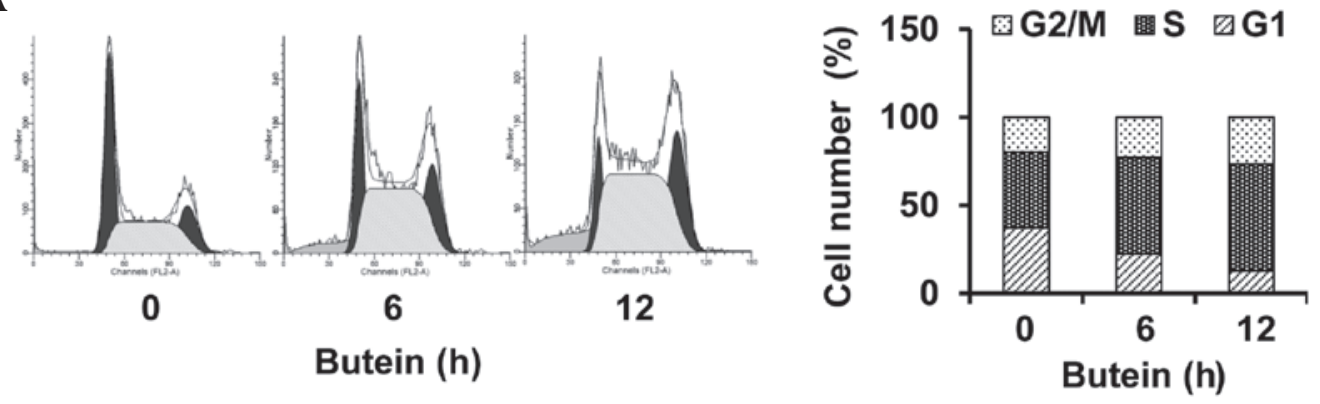

B

C
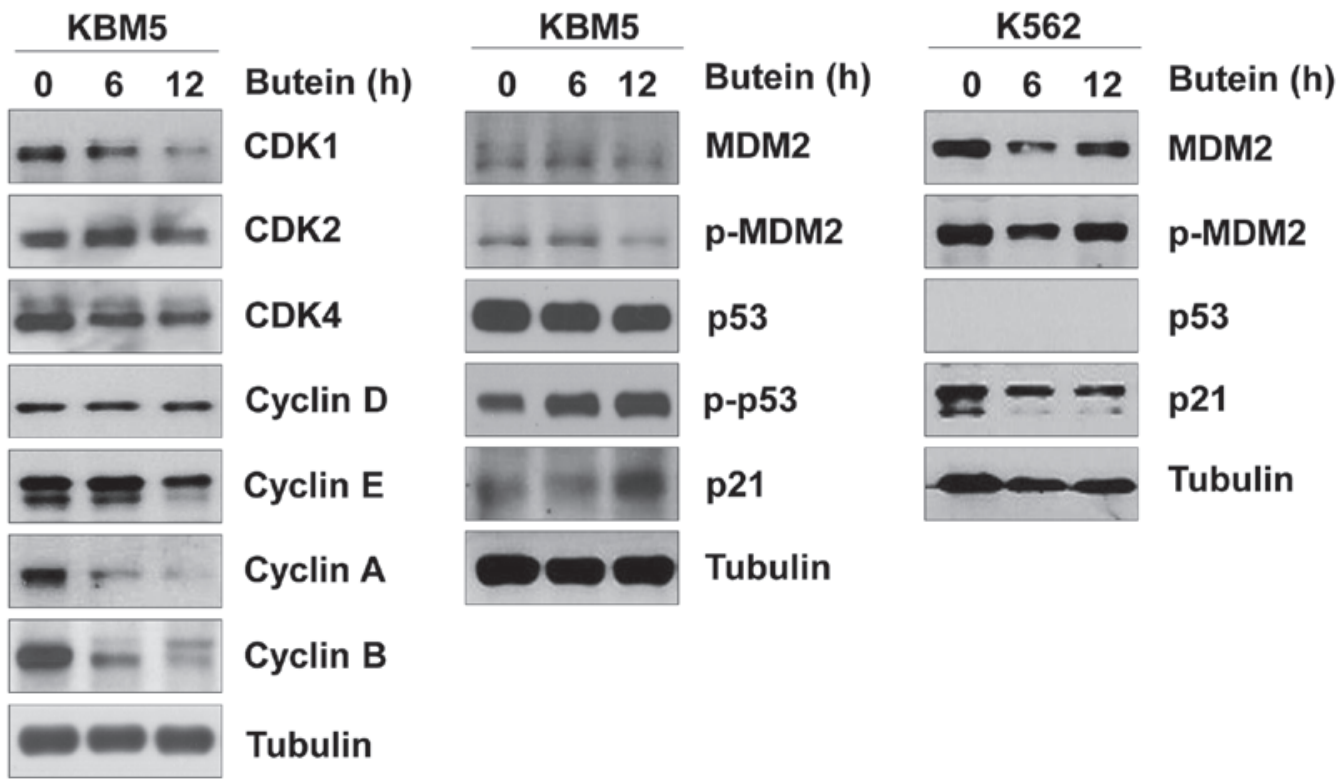

Figure 2. Effect of butein on the cell cycle of chronic myeloid leukemia cells. (A) The cells were treated with $5 \mu \mathrm{g} / \mathrm{ml}$ butein for the indicated durations and were subsequently stained with propidium iodide. (B and C) The cells were treated with $5 \mu \mathrm{g} / \mathrm{ml}$ butein for the indicated durations and the cells were subsequently harvested and proteins were extracted. The protein expression levels of numerous cell cycle associated proteins were determined by western blotting.

FACSCalibur (BD Biosciences, San Jose, CA, USA) with CellQuest Pro, version 5.2 software.

Statistical analysis. Student's t-test (Microsoft Excel version, 2007) was used to determine statistically significant differences between the cell lines. $\mathrm{P}<0.05$ was considered to indicate a statistically significant difference.

\section{Results}

Effect of butein on the cell viability of CML cells. Butein is a polyphenolic compound obtained from plants (Fig. 1A). To determine whether the cytotoxic effect of butein on CML cells was p53-dependent, CML cells expressing p53 (KBM5) or not (K562) were treated with butein at different concentrations and were subjected to viability assays. The expression patterns of p53 were confirmed in the KBM5 and K562 cells, to ensure that the p53 status was as described (Fig. 1B). Treatment with $5 \mu \mathrm{g} / \mathrm{ml}$ butein for $24 \mathrm{~h}$ reduced the viability of the KBM5 cells by $\sim 48.1 \%$, whereas it caused no effect on the viability of the K562 cells (Fig. 1C). Cell growth was subsequently measured for $72 \mathrm{~h}$ treatment. In accordance with the data from the cell viability assays, butein reduced KBM5 cell numbers, however, not K562 cell numbers. Additionally, the treatment prevented cell growth, even at $0.5 \mu \mathrm{g} / \mathrm{ml}$, while butein at $5 \mu \mathrm{g} / \mathrm{ml}$ marginally reduced $\mathrm{K} 562$ cell growth (Fig. 1D). Therefore, these data indicated that the expression of p53 in CML cells was crucial for butein sensitivity.

Effect of butein on the CML cell cycle. Next, whether butein affected the cell cycle of CML cells was assessed, since an abnormal cell cycle is tightly associated with cell death. Butein arrested the KBM5 cells in S-phase of the cell cycle (Fig. 2A). Furthermore, butein reduced the expression levels of CDK1, CDK4, cyclin A, cyclin B and cyclin E, and caused no affect on the expression levels of CDK2 and cyclin D (Fig. 2B). Therefore, butein-mediated changes in the expression levels of CDK/cyclin appeared to cause S-phase arrest. Furthermore, butein increased the phosphorylation of p53 and in turn, increased the expression of $\mathrm{p} 21$, while reducing phosphorylated and total expression levels of MDM2 in the KBM5 cells (Fig. 2C). In the K562 cells, butein marginally reduced the expression levels of p21 and MDM2 (Fig. 2C). Therefore, these data suggested that butein may impair the CML cell cycle by targeting p53 and its downstream effectors. 
A

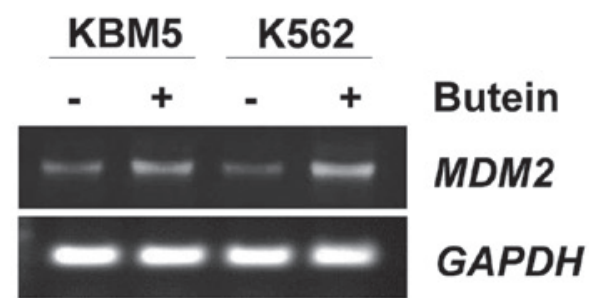

B

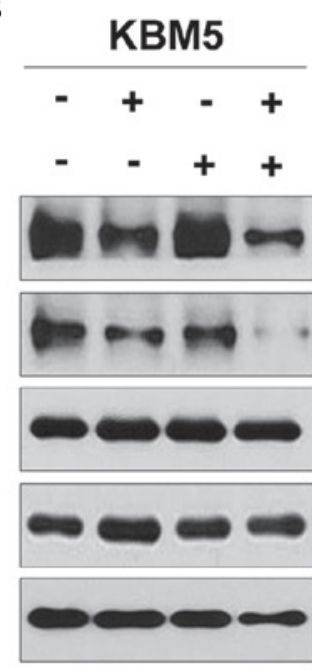

Butein

MG132

MDM2

p53

p-p53

Tubulin
p-MDM2

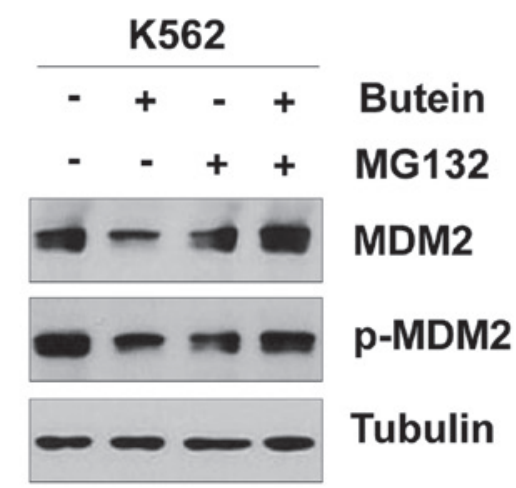

C KBM5

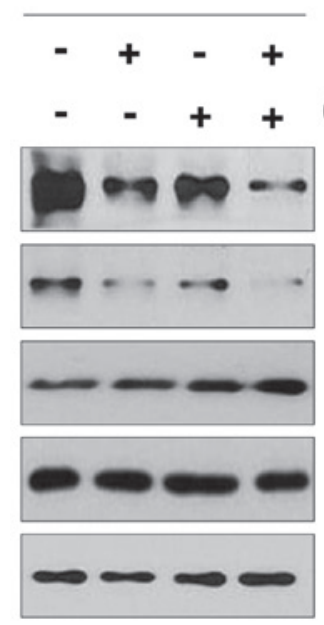

Butein

Cycloheximide

MDM2

p-MDM2

p53

p-p53

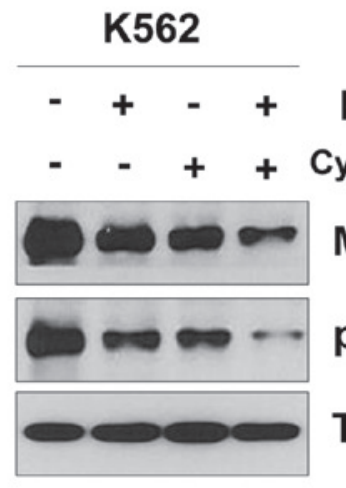

Butein

MDM2

p-MDM2

Tubulin

Figure 3. Effect of butein on the stability of MDM2. (A) The cells were treated with $5 \mu \mathrm{g} / \mathrm{ml}$ butein for $6 \mathrm{~h}$ and subsequently, the mRNA expression of MDM2 was determined by reverse transcription-polymerase chain reaction. The cells were treated with (B) $5 \mu \mathrm{g} / \mathrm{ml}$ butein and/or $5 \mu \mathrm{M} \mathrm{MG} 132 \mathrm{or}(\mathrm{C}) 5 \mu \mathrm{g} / \mathrm{ml}$ butein and/or $10 \mu \mathrm{g} / \mathrm{ml}$ cycloheximide, and the protein expression levels of p53, p-p53, MDM2 and p-MDM2 were assessed by western blotting. Tubulin was used as a loading control. p-, phosphorylated.

Effect of butein on the expression of MDM2 in CML cells. Butein reduced the expression of MDM2 independent of the p53 status (Fig. 2B). Therefore, the present study further examined the effect of butein on MDM2. When the KBM5 and K563 cells were treated with butein, the mRNA expression of MDM2 was increased (Fig. 3A). Since butein reduced the protein expression of MDM2, whether butein affected MDM2 protein stability was assessed. When the KBM5 cells were pretreated with MG132 and subsequently treated with butein, the protein expression of MDM2 was reduced (Fig. 3B), as earlier. Additionally, butein reduced the protein expression of MDM2 even in KBM5 cells treated with cycloheximide (Fig. 3C). Therefore, the MDM2 protein may be degraded in a proteasome-independent manner. Notably, treatment with MG132 rescued the butein-mediated MDM2 reduction in K562 cells (Fig. 3B). In addition, the protein expression of MDM2 was reduced even in the K562 cells treated with butein and cycloheximide (Fig. 3C). Therefore, these data suggested that butein-mediated MDM2 degradation may differ between the KBM5 and K562 cells. 
A

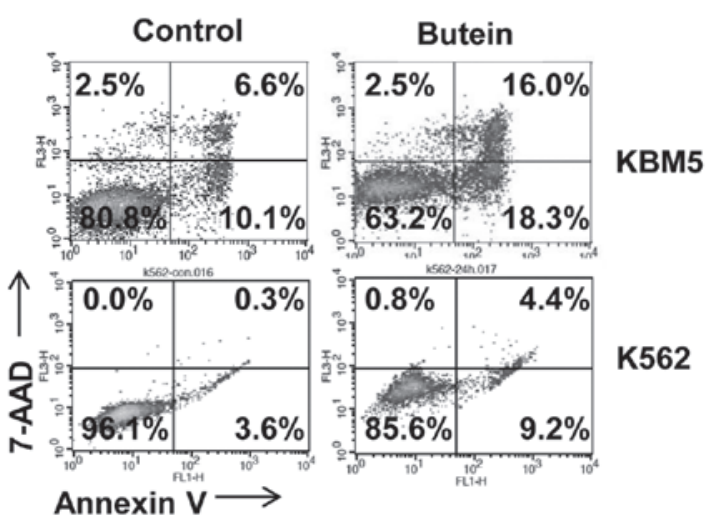

B

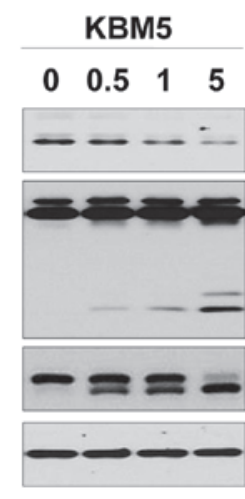

Butein
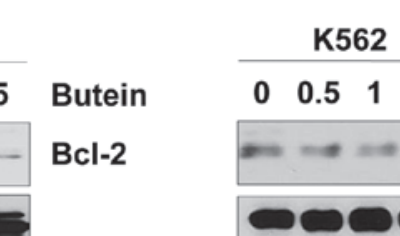

$\begin{array}{llll}0 & 0.5 & 1 & 5\end{array}$

Butein

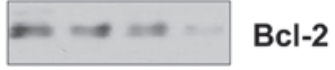

Caspase-3

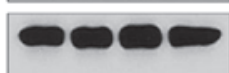

$\mathrm{Bcl}-2$

\section{Caspase-3}

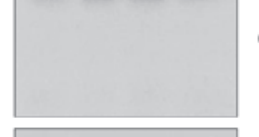

Caspase-3

PARP

Tubulin

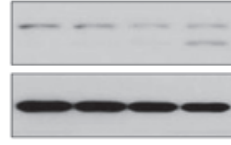

PARP

Tubulin

C

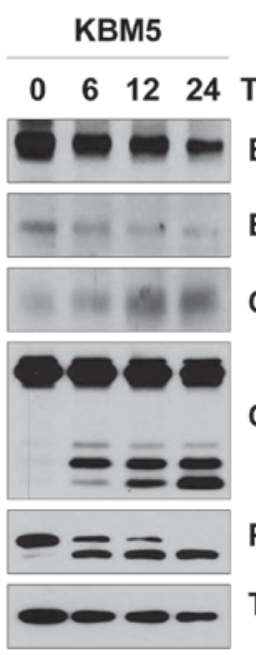

D

KBM5

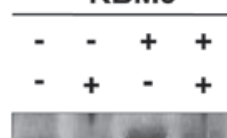

Butein

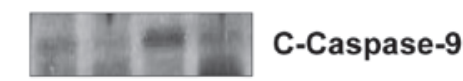

Bcl-2

Bcl-xL

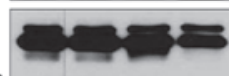

C-Caspase-9

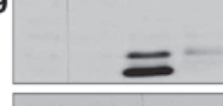

Caspase-3

Caspase-3

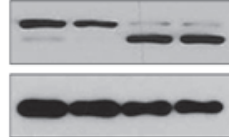

PARP

PARP

Tubulin

Tubulin

Figure 4. Effect of butein on the apoptosis of chronic myeloid leukemia cells. (A) The cells were treated with $5 \mu \mathrm{g} / \mathrm{ml}$ butein for $24 \mathrm{~h}$ and were subsequently stained with annexin V. The staining was assessed by flow cytometry. The cells were treated with (B) butein at the indicated concentrations for $24 \mathrm{~h}$, (C) $5 \mu \mathrm{g} / \mathrm{ml}$ butein for the indicated durations or (D) butein and/or $10 \mu \mathrm{M} \mathrm{Z-VAD-FMK}$ for $24 \mathrm{~h}$. The cells were harvested and the proteins were extracted to assess the protein expression levels of apoptosis associated proteins by western blotting. Tubulin was used as a loading control.

Effect of butein on the apoptosis of CML cells. To confirm that butein induced apoptotic cell death, the cells were stained with annexin V and 7-AAD. Treatment with butein for $24 \mathrm{~h}$ induced the apoptosis of KBM5 cells. This apoptotic effect was not as severe in the K562 cells (Fig. 4A). These data are consistent with the cell growth and viability assays, and support that p53 sensitizes butein-mediated apoptotic cell death.

Next, the effect of butein on the expression levels of proteins involved in apoptosis was assessed. Assessing Bcl-2 reduction, cleavage of PARP and the levels of caspase-3, it was demonstrated that KBM5 cells were more sensitive to butein compared with the K562 cells (Fig. 4B). Next, the effect of butein on apoptotic cell death at different treatment durations was determined. Butein caused apoptotic responses in KBM5 cells $6 \mathrm{~h}$ after treatment, as indicated by reduced levels of Bcl-2 and Bcl-xL, and increased cleaved forms of caspase-9, caspase-3 and PARP (Fig. 4C). To determine whether butein-mediated apoptosis involved the activation of caspases, Z-VAD-FMK, a caspase inhibitor was used. This inhibitor failed to reduce PARP cleavage, while it inhibited the cleavage of caspase-9 and caspase-3 (Fig. 4D). Therefore, 
these data suggested that butein may cause CML apoptosis via a p53-dependent and caspase-independent signaling pathway.

\section{Discussion}

The present study demonstrated for the first time, to the best of our knowledge, that butein-induced apoptosis of CML cells was dependent on the p53 expression pattern. Furthermore, in CML cells expressing p53 (KBM5) or those not expressing p53 (K562), butein mediated the degradation of MDM2 by different mechanisms. Therefore, while high doses of butein may result in the apoptosis of CML cells independently of p53 (22), low doses of butein selectively induced apoptotic cell death of p53-positive CML cells.

As mentioned above, higher doses of butein $(>20 \mu \mathrm{M})$ caused CML cell death. However, higher doses of butein appear to cause adverse effects. In the present study, lower doses of butein only caused apoptosis in p53-expressing CML cells. Consistently, butein affected the expression of the p53 downstream effector, p21, and regulated the stability of MDM2. Additionally, butein mediated cell cycle arrest in S-phase. Therefore, the butein-activated p53 pathway may arrest cells at S-phase, resulting in apoptotic cell death.

The present study further demonstrated that butein reduced the protein expression of MDM2 in both p53-expressing KBM5 and p53-null K562 cells, while butein increased the mRNA expression of $M D M 2$ independently of p53. The butein-mediated reduction of MDM2 protein appeared to follow two different mechanisms: Proteasome-dependent or -independent. Butein reduced the degradation of MDM2 in a proteasome-independent manner when p53 is expressed in CML cells. It was revealed that hispolon, a chemical compound from Phellinus species, reduces the protein expression of MDM2 via a lysosomal degradation pathway (23), which is similar to the butein effect on CML cells. Therefore, while the molecular mechanisms by which butein causes proteasome-independent degradation of MDM2 in p53-expressing cells remains to be elucidated, the present study suggested that p53 may decide the fate of MDM2, at least in CML cells.

In conclusion, the present study revealed the molecular mechanism by which butein caused the apoptosis of CML cells. While the butein effect on CML cells was revealed previously (17), the present study revealed for the first time, to the best of our knowledge, that butein-mediated apoptotic cell death was dependent on p53, even in CML. Therefore, it is worth investigating the effect of butein on cell death or growth retardation in other cancer cell types expressing wild-type p53.

\section{Acknowledgements}

This work was supported by a National Research Foundation of Korea (NRF) grant funded by the Korea government (Ministry of Science; no. 2007-0054931).

\section{References}

1. Gavel A: Chronic myelogenous leukemia; a case report. Can J Med Technol 8: 52-54, 1946.
2. Kantarjian HM, Smith TL, McCredie KB, Keating MJ, Walters RS, Talpaz M, Hester JP, Bligham G, Gehan E and Freireich EJ: Chronic myelogenous leukemia: A multivariate analysis of the associations of patient characteristics and therapy with survival. Blood 66: 1326-1335, 1985.

3. Frei E III, Tjio JH, Whang J and Carbone P: Studies of the philadelphia chromosome in patients with chronic myelogenous leukemia. Ann N Y Acad Sci 113: 1073-1080, 1964.

4. Trotta R, Vignudelli T, Candini O, Intine RV, Pecorari L, Guerzoni C, Santilli G, Byrom MW, Goldoni S, Ford LP, et al: $\mathrm{BCR} / \mathrm{ABL}$ activates mdm $2 \mathrm{mRNA}$ translation via the La antigen. Cancer Cell 3: 145-160, 2003.

5. Oliner JD, Kinzler KW, Meltzer PS, George DL and Vogelstein B: Amplification of a gene encoding a $\mathrm{p} 53$-associated protein in human sarcomas. Nature 358: 80-83, 1992.

6. Feinstein E, Cimino G, Gale RP, Alimena G, Berthier R, Kishi K, Goldman J, Zaccaria A, Berrebi A and Canaani E: p53 in chronic myelogenous leukemia in acute phase. Proc Natl Acad Sci USA 88: 6293-6297, 1991

7. Peterson LF, Mitrikeska E, Giannola D, Lui Y, Sun H, Bixby D, Malek SN, Donato NJ, Wang S and Talpaz M: p53 stabilization induces apoptosis in chronic myeloid leukemia blast crisis cells. Leukemia 25: 761-769, 2011.

8. Mahdi T, Alcalay D, Cognard C, Tanzer J and Kitzis A: Rescue of K562 cells from MDM2-modulated p53-dependent apoptosis by growth factor-induced differentiation. Biol Cell 90: 615-627, 1998.

9. Rizzo MG, Zepparoni A, Cristofanelli B, Scardigli R, Crescenzi M, Blandino G, Giuliacci S, Ferrari S, Soddu S and Sacchi A: Wt-p53 action in human leukaemia cell lines corresponding to different stages of differentiation. Br J Cancer 77: 1429-1438, 1998.

10. Yang EB, Zhang K, Cheng LY and Mack P: Butein, a specific protein tyrosine kinase inhibitor. Biochem Biophys Res Commun 245: 435-438, 1998.

11. Lee JC, Lee KY, Kim J, Na CS, Jung NC, Chung GH and Jang YS: Extract from Rhus verniciflua Stokes is capable of inhibiting the growth of human lymphoma cells. Food Chem Toxicol 42: 1383-1388, 2004.

12. Selvam C, Jachak SM and Bhutani KK: Cyclooxygenase inhibitory flavonoids from the stem bark of Semecarpus anacardium Linn. Phytother Res 18: 582-584, 2004.

13. Chan SC, Chang YS, Wang JP, Chen SC and Kuo SC: Three new flavonoids and antiallergic, anti-inflammatory constituents from the heartwood of Dalbergia odorifera. Planta Med 64: 153-158, 1998.

14. Cho SG, Woo SM and Ko SG: Butein suppresses breast cancer growth by reducing a production of intracellular reactive oxygen species. J Exp Clin Cancer Res 33: 51, 2014.

15. Lee JO, Moon JW, Lee SK, Kim SM, Kim N, Ko SG, Kim HS and Park SH: Rhus verniciflua extract modulates survival of MCF-7 breast cancer cells through the modulation of AMPK-pathway. Biol Pharm Bull 37: 794-801, 2014.

16. Khan N, Adhami VM, Afaq F and Mukhtar H: Butein induces apoptosis and inhibits prostate tumor growth in vitro and in vivo. Antioxid Redox Signal 16: 1195-1204, 2012.

17. Kim N: Butein sensitizes human leukemia cells to apoptosis induced by tumor necrosis factor-related apoptosis inducing ligand (TRAIL). Arch Pharm Res 31: 1179-1186, 2008.

18. Iwashita $K$, Kobori $M$, Yamaki $K$ and Tsushida $T$ : Flavonoids inhibit cell growth and induce apoptosis in B16 melanoma 4A5 cells. Biosci Biotechnol Biochem 64: 1813-1820, 2000.

19. Lubbert M, Miller CW, Crawford L and Koeffler HP: p53 in chronic myelogenous leukemia. Study of mechanisms of differential expression. J Exp Med 167: 873-886, 1988.

20. Sen S, Takahashi R, Rani S, Freireich EJ and Stass SA: Expression of differentially phosphorylated $\mathrm{Rb}$ and mutant p53 proteins in myeloid leukemia cell lines. Leuk Res 17: 639-647, 1993

21. Zell JA, Ramakrishnan R and Rathinavelu A: Regulation of mdm2 mRNA expression in human breast tumor-derived GI-101A cells. Life Sci 71: 2331-2339, 2002.

22. Harikumar KB, Kunnumakkara AB, Ahn KS, Anand P, Krishnan S, Guha S and Aggarwal BB: Modification of the cysteine residues in IkappaBalpha kinase and NF-kappaB (p65) by xanthohumol leads to suppression of NF-kappaB-regulated gene products and potentiation of apoptosis in leukemia cells Blood 113: 2003-2013, 2009.

23. Lu TL, Huang GJ, Wang HJ, Chen JL, Hsu HP and Lu TJ: Hispolon promotes MDM2 downregulation through chaperone-mediated autophagy. Biochem Biophys Res Commun 398: 26-31, 2010. 